\title{
Students' Engagement dalam Proses Pembelajaran Daring Melalui Lesson Study pada Mata Kuliah Kalkulus Integral
}

\author{
Iin Ariyanti ${ }^{1}$, Fikrie ${ }^{2}$, Dyta Setiawati Hariyono ${ }^{3}$ \\ ${ }^{1}$ Program Studi Pendidikan Matematika, Fakultas Keguruan dan Ilmu Pendidikan, Universitas Muhammadiyah Banjarmasin \\ 2,3Program Studi Psikologi, Fakultas Psikologi, Universitas Muhammadiyah Banjarmasin \\ Jl. Gubernur Syarkawi, Handil Bakti, Kalimantan Selatan, 70126 \\ iin.ariyanti1105@gmail.com
}

\begin{abstract}
Students' engagement in the learning process is very important to identificate because it affects student success in the learning process. Students' engagement is a psychological process that shows the attention, interest, investment, effort, and involvement of students which is poured into learning work includes emotional, cognitive, and behavioral engagement. This study aimed to see students' engagement in the online learning process through lesson study because from the beginning, the learning process had good planning (plan, do \& see). This study used a qualitative-quantitative approach where the qualitative approach in this study aimed to produce an in-depth description of student engagement based on speech, writing and behavior observed by the observer during the stage of "do" lesson study while the quantitative approach aimed to determine students' engagement from the point of students' views through a survey. Based on the results of the study, it was found that there were differences in the qualitative and quantitative results of student engagement in integral calculus students. In the qualitative analysis, only 12 out of 22 people showed student engagement during class discussions and/or group discussions. The rest are classified as not showing visible participation, only being seen taking notes, writing, or counting as well as facial expressions that show trying to understand the material presented, but there is still no involvement even though they are in a smaller group. Meanwhile, based on the results of quantitative analysis, there are no students who feel that their student's engagement is low both from the emotional, cognitive, and behavioral aspects.
\end{abstract}

Keywords: Students’ engagement, Online Learning, Lesson Study, Students’ Involvement

\begin{abstract}
Abstrak
Identifikasi students' engagement atau keterlibatan siswa dalam proses pembelajaran sangat penting karena mempengaruhi keberhasilan siswa dalam proses pembelajaran. Keterlibatan siswa adalah sebuah proses psikologis yang menunjukkan perhatian, minat, investasi, usaha dan keterlibatan para mahasiswa yang dicurahkan dalam pekerjaan belajar yang meliputi keterlibatan emosional, keterlibatan kognitif maupun keterlibatan behaviour. Penelitian ini bertujuan melihat students' engagement mahasiswa dalam proses pembelajaran daring melalui lesson study karena sejak awal proses pembelajaran dilakukan perencanaan yang baik (plan, do \& see). Penelitian ini menggunakan pendekatan kualitatif-kuantitatif dimana pendekatan kualitatif dalam penelitian ini bertujuan menghasilkan uraian yang mendalam mengenai student engagement siswa berdasarkan ucapan, tulisan dan perilaku yang diamati oleh observer pada saat tahap "do" lesson study sedangkan pendekatan kuantitatif bertujuan untuk mengetahui student engagement dari sudut pandang siswa melalui survey. Berdasarkan hasil penelitian diperoleh bahwa terdapat perbedaan hasil kualitatif dan kuantitatif student engagement pada mahasiswa kalkulus integral. Pada analisis kualitatif, hanya 12 dari 22 orang yang menunjukkan sikap student engagement pada saat diskusi kelas dan/atau diskusi kelompok. Sisanya tergolong tidak menunjukkan partisipasi yang terlihat, hanya sebatas terlihat mencatat, menulis, atau menghitung serta raut muka yang menunjukkan mencoba memahami materi yang disampaikan, namun tetap tidak adanya keterlibatan meskipun berada di kelompok yang lebih kecil. Sedangkan berdasarkan hasil analisis kuantitatif, tidak ada mahasiswa yang merasa student's engagementnya rendah baik dari aspek emosional, kognitif maupun behaviour Kata kunci: Students' engagement, Pembelajaran daring, Lesson Study, Keterlibatan mahasiswa
\end{abstract}

Copyright (c) 2022 Iin Ariyanti, Fikrie, Dyta Setiawati Hariyono

$\bowtie$ Corresponding author: Iin Ariyanti

Email Address: iin.ariyanti1105@gmail.com (Jl. Gubernur Syarkawi, Handil Bakti, Kalimantan Selatan, 70126) Received 11 January 2022, Accepted 01 February 2022, Published 09 February 2022

\section{PENDAHULUAN}

Pandemi Covid 19 yang melanda seluruh negara termasuk di Indonesia telah mempengaruhi banyak sektor, tak terkecuali bidang pendidikan. Dalam memutus penyebaran pandemi covid 19 di 
sekolah maupun perguruan tinggi, pemerintah mengeluarkan kebijakan untuk menerapkan social distancing dalam kegiatan pembelajaran. Bidang pendidikan yang biasanya melaksanakan pembelajaran tatap muka $100 \%$ di sekolah ataupun perguruan tinggi harus mengalami perubahan yang sangat signifikan dimana pembelajaran yang awalnya dilakukan tatap muka berganti menjadi pembelajaran secara daring. Kebijakan beralihnya pembelajaran tatap muka menjadi pembelajaran daring ini merupakan upaya yang diterapkan pemerintah dalam membatasi interaksi masyarakat di sektor pendidikan (Siahaan, 2020).

Pembelajaran daring merupakan salah satu pendekatan dalam pembelajaran jarak jauh dengan memanfaatkan berbagai teknologi yang memanfaatkan jaringan internet dengan tujuan menjangkau suatu target kelompok yang besar dan luas (Dewi \& Sadjiarto, 2021). Di masa pandemi ini, pembelajaran daring beralih tujuan dari menjangkau kelompok yang besar dan luas menjadi suatu kebutuhan akan sarana dalam memfasilitasi pembelajaran antara guru dan peserta didik ketika pembelajaran tatap muka tidak bisa dilakukan. Menurut Belawati (2020) pembelajaran daring tidak hanya sekedar memberikan materi pembelajaran secara online, akan tetapi terdapat interaksi yang terjadi selama proses pembelajaran. Adapun interaksi pembelajaran tersebut terjadi antara peserta didik dan pengajar, antara peserta didik ataupun antara peserta didik dengan materi pembelajaran itu sendiri.

Pembelajaran daring memiliki kekurangan tersendiri. Mahasiswa kesulitan beradaptasi dengan situasi tersebut sehingga menyebabkan mahasiswa kurang terlibat secara aktif dalam proses pembelajaran secara daring. Hal ini dirasakan selama pelaksanaan pembelajaran daring pada mata kuliah prasyarat kalkulus integral yaitu kalkulus differensial di semester ganjil. Hanya beberapa mahasiswa yang terlihat cukup aktif pada perkuliahan. Hal ini sejalan dengan pendapat oleh Widiyono (2020) bahwa perkuliahan daring memberikan gambaran umum tentang kurang optimalnya pemahaman materi dan banyaknya tugas yang diberikan pada mahasiswa sehingga mengakibatkan proses perkuliahan kurang efektif.

Meyers (2008) menyatakan bahwa pembelajaran daring membutuhkan perhatian penuh bagi dosen untuk membantu mahasiswa terlibat dalam pembelajaran serta bagaimana merancang kelas virtual yang dapat meningkatkan rasa kebersamaan. Oleh karena itu, guru perlu melakukan lesson study dalam meminimalisir permasalahan dalam proses pembelajaran daring. Pada kegiatan lesson study, dosen-dosen dapat bekerja secara kolaboratif dalam merumuskan tujuan pembelajaran, merencanakan, melaksanakan dan mengamati rancangan pembelajaran yang dirancang, mengamati pembelajaran dari segi keterlibatan, dan tingkah laku mahasiswa dan mendiskusikan serta memperbaiki pembelajaran dan pendekatan mengajar berdasarkan hasil observasi (Takahashi \& Yoshida, 2004). Dengan kata lain, pertama-tama dosen membentuk tim yang terdiri atas dosen model dan observer, selanjutnya dosen merencanakan tujuan pembelajaran yang ingin dicapai serta desain pembelajaran yang sesuai agar dapat memancing keterlibatan mahasiswa dalam pembelajaran (tahap plan), kemudian dosen melaksanakan pembelajaran berdasarkan rancangan yang telah dibuat (tahap 
do) dimana observer diminta untuk mengamati keterlibatan mahasiswa yang terjadi pada diskusi kelas maupun diskusi kelompok, terakhir dosen model bersama observer melakukan evaluasi berdasarkan pengamatan pada kegiatan pembelajaran (tahap see).

Menurut Lewis (2000) lesson study mempunyai pengaruh yang baik terhadap pembelajaran antara lain memperoleh feedback terhadap pengajaran yang dilakukan dan memperoleh ide baru dengan melihat pengajaran dosen lain, menajamkan indera dalam melihat mahasiswa belajar, berkesempatan dalam memahami topik atau pendekatan yang baru dari pemikiran teman sejawat, serta pendapat- pendapat berbeda yang diberikan teman sejawat memperbesar kemungkinan dosen dalam menemukan cara yang lebih baik dalam pengajaran.

Identifikasi keterlibatan siswa dalam proses pembelajaran sangat penting, karena keterlibatan siwa menjadi faktor penting dalam mempengaruhi keberhasilan siswa dalam proses pembelajaran (Fredricks et al., 2016; Wang \& Holcombe, 2010). Keterlibatan siswa sendiri adalah sebuah proses psikologis yang menunjukkan perhatian, minat, investasi, usaha dan keterlibatan para mahasiswa yang dicurahkan dalam pekerjaan belajar yang meliputi (1) keterlibatan emosi, yang menunjukkan minat, nilai, dan emosi misalnya: perasaan di kelas, perasaan terhadap kampus dan dosen, perasaan terhadap perlakuan, disiplin dan motivasi, perasaan memiliki, perasaan positif, dan menghargai prestasi akademik, (2) keterlibatan kognitif yakni persepsi terhadap motivasi, usaha keras dan penggunaan strategi. Ini mencakup investasi psikologis dalam belajar, usaha keras dalam belajar, keseriusan berkuliah, keinginan bekerja melebihi yang dipersyaratkan, pilihan yang menantang, disiplin, perencanaan dan strategi belajar, keluwesan dalam memecahkan masalah, memilih bekerja keras, dan (3) keterlibatan perilaku, yakni mengerjakan tugas dan mengikuti peraturan , meliputi: (a) perilaku yang positif, yaitu perilaku yang mengilustrasikan usaha, ketekunan, konsentrasi, perhatian, mengajukan pertanyaan, menyumbang pada diskusi kelas, mengikuti aturan, belajar, menyelesaikan tugas, berpartisipasi dalam aktivitas yang terkait. (b) Absennya perilaku yang mengganggu, seperti hadir dan tidak membuat kekacauan di kelas (Dharmayana et al., 2012). Students' engagement dihasilkan dari motivasi intrinsik atau kebutuhan individu yang membuat mereka memiliki perasaan positif dan melanjutkan praktik mereka dengan ketekunan dan kepercayaan diri, sehingga meningkatkan students' engagement merupakan upaya yang dapat menentukan keberhasilan akademik (Fikrie \& Ariani, 2019). Tinggi rendahnya keterlibatan mahasiswa (students' engagement) dapat dicerminkan dari skor yang diperoleh dalam mengerjakan Skala Keterlibatan Siswa (SKS).

Syah (2009) menjelaskan bahwa ada tiga faktor yang dapat menentukan keberhasilan siswa dalam proses pembelajaran yaitu faktor internal, external dan pendekatan belajar. Faktor internal sendiri meliputi kondisi fisik (kesehatan dan cacat tubuh) dan psikologi (perhatian, intelegensi, minat, bakat, motif, kematangan dan kesiapan), faktor external meliputi keluarga (relasi di dalam keluarga, suasana rumah, ekonomi keluarga), lingkungan sekolah (metode mengajar, kurikulum, relasi guru dengan siswa, relasi antar siswa, media pembelajaran, kedisiplinan sekolah) dan masarakat (media massa, teman bergaul dan partisipasi siswa di masyarakat) dan faktor pendekatan belajar yaitu strategi 
dan metode yang dilakukan oleh siswa untuk memahami pembelajaran. Selain itu menurut Peterson (2006), bahwa keberhasilan proses pembelajaran tidak hanya merujuk pada dimensi prestasi belajar tetapi juga menitikberatkan pada pembentukan karakter serta apakah siswa merasakan kebahagian ketika mereka berada di sekolah. Hal-hal tersebut tersebut tercakup dalam setiap dimensi ketelibatan siswa yang telah dijelaskan sebelumnya. Hal ini yang membuat keterlibatan siswa secara aktif penting untuk diperhatikan.

Berdasarkan uraian yang dikemukakan di atas, maka proses pembelajaran daring melalui lesson study diharapkan dapat membantu mengidentifikasi keterlibatan mahasiswa dalam proses pembelajaran karena sejak awal proses pembelajaran dilakukan perencanaan yang baik (plan, do \& see). Selain itu melalui observasi pada tahap do yang terdapat pada lesson study, keterlibatan mahasiswa dapat teramati oleh observer secara langsung dan menjadi bahan pengamatannya dan disampaikan melalui tahap see. Dengan kata lain tujuan penelitian ini adalah untuk melihat students' engagement dalam proses pembelajaran daring melalui lesson study pada mata kuliah kalkulus integral. Permasalahan yang akan dijawab dalam penelitian ini adalah "Bagaimana students' engagement dalam proses pembelajaran daring melalui lesson study pada mata kuliah kalkulus integral?".

\section{METODE}

Desain penelitian ini menggunakan mixed method atau kualitatif- kuantitatif. Penelitian dengan pendekatan kualitatif dalam penelitian ini bertujuan agar mampu menghasilkan uraian yang mendalam mengenai student engagement siswa berdasarkan ucapan, tulisan dan perilaku yang diamati oleh observer pada saat tahap "do" lesson study pada mata kuliah kalkulus integral. Sedangkan pendekatan kuantitatif bertujuan untuk mengetahui student engagement dari sudut pandang siswa melalui survey dengan data penelitian berupa angka skala likert. Sumber data penelitian ini adalah mahasiswa yang mengambil mata kuliah kalkulus integral tahun akademik 2020-2021 di Universitas Muhammadiyah Banjarmasin. Adapun mahasiswa yang hadir pada saat pelaksanaan pembelajaran dan mengisi survey angket student's engagement sebanyak 22 orang.

Teknik pengumpulan data dalam penelitian ini menggunakan observasi, wawancara, dokumen serta angket. Teknik pengumpulan data observasi dilakukan pada saat tahap "do" lesson study. Observer terdiri dari 5 orang dimana 2 orang dengan latar belakang S2 psikologi dan 3 orang dengan latar belakang S2 pendidikan matematika. Observasi dilakukan pada saat kegiatan proses pembelajaran daring pada tahapan lesson-study "do" dengan hasil data kualitatif berupa catatan lembar observasi selama pembelajaran berlangsung. Sedangkan Teknik wawancara dalam penelitian ini dilakukan pada tahap see dimana observer menyampaikan secara langsung penuturannya mengenai hasil pengamatan yang diperoleh pada saat tahap do untuk mengkonfirmasi lembar observasi student engagement yang dituliskan oleh observer. Adapun dokumen berupa hasil rekaman zoom pada saat tahap do dan see. Teknik pengumpulan data angket dilakukan di akhir proses pembelajaran pada 
tahapan lesson study "do" dengan menyebarkan skala angket students' engagement pada mahasiswa yang mengikuti mata kuliah kalkulus integral dengan hasil data kuantitatif skala likert.

Data kualitatif dalam penelitian ini adalah hasil pengamatan observer berupa ucapan, tulisan dan perilaku siswa pada saat tahap "do" lesson study mengenai student engagement pada mahasiswa kalkulus integral. Data kualitatif dianalisis menggunakan teknik analisis model Miles dan Huberman yang terdiri dari data reduction, data display, dan conclusion drawing/verification. Data reduction artinya peneliti merangkum, memilih hal-hal yang penting, dan mencari pola dari data-data tersebut. Data display artinya data tersebut disusun dalam suatu pola agar lebih mudah dipahami dan disajikan dalam bentuk bagan. Setelah dilakukan data reduction dan data display maka selanjutnya adalah conclusion drawing/verification. Kesimpulan dalam tahap ini masih bersifat sementara sampai buktibukti yang diperoleh valid dan konsisten.

Sedangkan data kuantitatif berupa angket students' engagement pada mahasiswa kalkulus integral. Data kuantitatif selanjutnya ditabulasi dan diinterpretasi menggunakan acuan standar pengelompokkan skor individu berdasarkan model distribusi normal pada skala ordinal. Adapun penggolongan hasil angket student engagement dibagi menjadi 3 jenis tingkatan kategori yang dapat dilihat pada tabel berikut (Azwar, 2015).

Tabel 1. Tingkatan Kategori Student Engagement

\begin{tabular}{|c|l|}
\hline & Kategori \\
\hline $\boldsymbol{X}<(\boldsymbol{\mu}-\mathbf{1 \sigma})$ & Rendah \\
\hline$(\boldsymbol{\mu}-\mathbf{1 \sigma}) \leq \boldsymbol{X}<(\boldsymbol{\mu}+\mathbf{1} \boldsymbol{\sigma})$ & Sedang \\
\hline$(\boldsymbol{\mu}+\mathbf{1} \boldsymbol{\sigma}) \leq \boldsymbol{X}$ & Tinggi \\
\hline
\end{tabular}

\section{HASIL DAN DISKUSI}

\section{Hasil Analisis Kualitatif}

Hasil analisis kualitatif diperoleh berdasarkan hasil pengamatan observer pada saat tahap "do" pada mata kuliah kalkulus integral yang terbagi mnjadi pengamatan berdasarkan pada aspek cognitive engagement, behavioral engagement, dan emotional engagement melalui lembar observasi. Lembar observasi tersebut dikonfirmasi pada tahap lesson study "see" dimana observer menyampaikan hasil observasi yang diperoleh bersama-sama dosen model dan observer yang lain.

\section{Observer ke-1}

"Berdasarkan hasil lembar observasi dan penuturan observer ke -1 pada tahap see diperoleh bahwa dari yang teramati oleh observer, mahasiswa yang aktif Ketika di diskusi kelas adalah MS, Myd, Ftr,MF, NH, dan And itu terlihat aktif. Pada saat berada di lingkup yang lebih kecil yaitu diskusi kelompok terdapat 2 mahasiswa yang awalnya diskusi kelas tidak terlihat aktif namun aktif mengerjakan/diskusi di kelompoknya yaitu TA dan MH. Selain itu, Fhr baik diskusi kelas maupun kelompok terlihat diam dan tidak aktif". 


\section{Observer ke-2}

"Mahasiswa YR, MS, Myd, dan And behaviornya terlihat dari intensitas usaha untuk terlibat pada saat dosen mengajar. Mahasiswa tadi merupakan mahasiswa yang level kognitif, behavior dan emotionalnya tinggi. Mahasiswa yang lainnya juga terlihat tapi kurang secara emosional dan kognitif. Pada saat diskusi kelompok yang sangat menguasai dan memahami materi adalah Myd dan antusias agar aktif bersama-sama. Mahasiwa yang kurang dalam hal kognitif engagement pada saat diskusi kelompok adalah hdy".

\section{Observer ke-3}

"Saya setuju dengan observer ke-1 bahwa Fhr jarang bicara hingga berkedip saja juga jarang sepertinya. Selama saya memperhatikan dia tipe orang yang memperhatikan tetapi tidak ada gerakan sama sekali, berbeda dengan teman-temannya mungkin memperhatikan tetapi ada reaksi seperti menunduk atau geser badan. Mahasiswa yang paling aktif no 1 adalah Myd, ke-2 MS, dan MF dia tidak terlalu aktif tetapi pada saat di akhir akhir mengikuti tanya jawab Ketika dosen memberikan soal, YR berpartisipasi di awal-awal dan antusias tetapi pada saat diakhir dia banyak diam karena memang banyak teman lain berpartisipasi juga. Pada saat diskusi kelompok, Ftr paling aktif, pintar, dan cepat mengerjakan namun kurang teliti, MF juga aktif tetapi agak kurang focus karena ada yg mengajak ngobrol, CL Ketika diskusi kelas tidak terlalu banyak bicara dan hanya senyum tetapi pada saat diskusi kelompok berani untuk menjawab".

\section{Observer ke-4}

"Pada saat apersepsi, yang berpartisipasi menjawab pertanyaan dosen MS, Myd, dan Ftr. Pada saat awal materi yang terlihat sangat memperhatikan dengan tatapan ingin tahu yang besar adalah Myd, MS, dan And. Pada saat tanya jawab dengan dosen pada saat diskusi kelas YR dan Ftr memberikan tanggapan terhadap pertanyaan dosen. Pada saat materi contoh luas di bawah sumbu $\mathrm{X}$ yang berpartisipasi menjawab adalah MS, MF,dan Ftr. Beberapa orang yang terlihat menulis, mungkin mencoba menghitung atau mencatat adalah MS, Fhr, Ftr, Hdy. Pada materi dua kurva partisi tegak yang aktif menjawab pertanyaan adalah MF dan And dan yang terlihat menulis pada saat itu adalah Ash, Myd, Ftr, YR, Fhr, Ftr, dan RA. Pada materi partisi mendatar yang terlihat menulis Fhr, TA, Myd, WN, Hdy, CL, SF, Ftr, MH tapi terlihat menulis dan menghitung dan tidak menjawab pertanyaan. Partisipasi kognitif yang sangat terlihat MS, Myd, Ftr, And, dan YR”.

"Pada saat diskusi kelompok 4, anggotanya yaitu RR, HJ, dan NH. Mereka mengerjakan sendiri-sendiri. NH menanyakan apakah sudah selesai atau belum no 1. Akan tetapi tidak ada respon. Kemudian NH menyampaikan hasil jawabannya, ternyata hasil jawaban mereka bertiga berbeda-beda. HJ share screen hasil pekerjaannya no 1 dan NH menyadari bahwa dia salah hitung. Soal no 2 mereka kesulitan menggambarkan grafik pada geogebra karena kendala device. Akhirnya HJ yang share screen gambar grafik no 2. Mereka kehabisan waktu dalam mengarsir dan menggambar sehingga belum sempat menghitung no 2. Jadi jika dikaitkan dengan behavior, emosional, dan kognitif, mereka sama-sama datar, diam, antusiasnya kurang tetapi berusaha mengerjakan sendiri-sendiri. Behavior 
terlihat karena mereka berusaha walaupun usahanya sendiri-sendiri dalam mengerjakan di kelompoknya".

\section{Observer ke-5}

"Hasil observasi pembelajaran secara umum/diskusi kelas, saya coba lihat permenit perfase satuan waktu. Secara umum 15 menit pertama dan 15 menit kedua, pada aspek behavior hanya beberapa orang yang terlibat aktif serta memiliki usaha dan inisiatif yang baik sekitar $4-5$ orang yaitu Myd, Fhr, MF, Asy. Hampir semua mahasiswa perempuan yang terlibat memiliki usaha untuk memahami materi sementara hampir semua mahasiswa laki-laki hanya menimpali ketika teman perempuannya menjawab. Pada 15 menit ketiga dan keempat hampir sama, hanya beberapa orang terlibat memiliki usaha atau berusaha untuk memahami materi yang disampaikan. Pada 15 menit keempat terlihat dari raut mukanya mencoba menjawab atau memahami materi yang disampaikan meskipun pandangan menunduk tidak terus ke kamera tetapi melakukan usaha untuk menjawab.

"Pada aspek emotional engagement hampir semua terlihat datar tidak antusias, tidak semangat 15 menit awal dan kedua. Secara emosi mereka datar seperti tidak ada semangat dan biasa saja entah karena karakter atau tidak tertarik dengan proses pembelajaran yang dilakukan. Pada 15 menit ketiga dan keempat hampir sama, beberapa mahasiswa terlihat bersemangat dan tertarik dengan materi yang disampaikan. Pada apek kognitif engagement 15 menit pertama hingga 15 menit ketiga hampir semua mahasiswa tetap berkonsentrasi dan focus dengan apa yang disampaikan dosen model. Selain itu, di 15 menit ketiga ini, mahasiswa yang aktif ketika ditanya oleh dosen, memberikan feedback ketika mereka tidak bisa memahami, mereka langsung bertanya. Hal ini termasuk kedalam aspek kognitif. Pada 15 menit keempat berdasarkan observasi dari raut muka dan tubuh, mereka masih bisa mempertahankan konsentrasi dan fokusnya".

"Pada diskusi kelompok, terdapat 3 orang yang hadir dari 5 orang yaitu DOR, Ash, MS. Mahasiswa yang paling aktif MS dan Ash, sementara DOR pasif, jika diberitahu temannya baru bersuara. Pada saat diskusi kelompok DOR diam memperhatikan apa yang disampaikan temannya. Jika dilihat dari aspek behavior, DOR memiliki usaha yang sangat minim dibandingkan MS dan Ash. Ash inisiatif untuk melakukan share screen dan ketika ada pertanyaan dan kesulitan Ash mencoba untuk menjawab. MS jelas paling aktif dan sangat berinisiatif, 2 dari 3 soal MS yang mengerjakan. Pada aspek emosional DOR sangat minimal yaitu datar dan biasa saja sedangkan MS dan Ash antusias dari awal hingga akhir. Dari segi kognitif, DOR berkonsentrasi dan focus, hanya saja diam dan pasif sedangkan yang terlihat sangat berkonsentrasi dan punya focus yang baik adalah MS dan Ash. Jika disimpulkan DOR rendah, Ash sedang, dan MS tinggi dalam antusias mengerjakan tugas".

Secara keseluruhan dari penuturan observer diperoleh bahwa:

1. mahasiswa menunjukkan keaktifan mereka dari bagaimana mereka antusias dalam memberikan feedback kepada dosen pada saat diskusi kelas.

2. mahasiswa menunjukkan keaktifan pada saat berusaha memahami dan menyelesaikan soal-soal melalui diskusi kelompok. Mahasiswa dapat mengekpresikan pendapatnya, karena dibuat dalam 
lingkup yang lebih kecil sehingga memudahkan mahasiswa dalam berkomunikasi menyampaikan pendapatnya.

3. Ada pula mahasiswa yang ketika diskusi kelas tidak banyak bicara dan dilayar hanya senyumsenyum tetapi ketika diskusi kelompok ternyata berani untuk menjawab.

4. Mahasiswa kurang aktif dalam berdiskusi dengan respon hanya sekali bersuara menanggapi teman-temannya yang bertanya, selebihnya ia hanya senyum-senyum saja.

\section{Analisis Kuantitatif}

Angket Student Engagement diberikan kepada mahasiswa di akhir pembelajaran daring kalkulus integral. Angket yang diberikan menggunakan format repon skala likert yang terdiri dari Sangat Tidak Setuju, Tidak Setuju, Netral, Setuju dan Sangat Setuju terhadap 27 item pernyataan yang disediakan. Adapun item pernyatan tersebut terbagi menjadi pernyataan favourabel dan unfavourable. Skor angket student engagement dari rentang sangat tidak setuju hingga sangat setuju untuk pernyataan favourable adalah skor 1 sampai 5, sedangkan pernyataan unfavourable berlaku sebaliknya yaitu skor 5 sampai skor 1. Dapat dikatakan bahwa rentang skor minimumnya adalah $27 \mathrm{x}$ $1=27$ hingga rentang skor maksimumnya adalah $27 \times 5=135$. Luas jarak sebarannya yaitu skor maksimum -skor minimum atau 135-27=108. Maka $\sigma=\frac{108}{6}=18$ dan $\mu=\frac{135+27}{2}=81$. Sehingga kategori student engagement siswa berdasarkan tingkatan kategori di atas adalah tabel 2 berikut.

Tabel 2. Tingkatan Kategori Student Engagement

\begin{tabular}{|c|c|}
\hline & Kategori \\
\hline $\boldsymbol{X}<63$ & Rendah \\
\hline $63 \leq X<99$ & Sedang \\
\hline $\mathbf{9 9} \leq \boldsymbol{X}$ & Tinggi \\
\hline
\end{tabular}

Gambaran student engagement berdasarkan hasil angket mahasiswa dengan kategori, tinggi, sedang, dan rendah dapat dilihat pada tabel 3 berikut.

Tabel 3. Gambaran Students' Engagement

\begin{tabular}{|c|c|c|}
\hline Kategori & Frekuensi & Prosentase \\
\hline Tinggi & 13 & $59 \%$ \\
\hline Sedang & 9 & $41 \%$ \\
\hline Rendah & 0 & $0 \%$ \\
\hline
\end{tabular}

Berdasarkan tabel 3 tersebut, maka dapat disimpulkan bahwa secara keseluruhan tidak ada mahasiswa yang menganggap dirinya memiliki student engagement yang rendah. Lebih dari 50\% mahasiswa menganggap dirinya memiliki student engagement yang tinggi dan sisanya sedang. Selanjutnya angket student engagement tersebut dianalisis per aspek yaitu aspek kognitif, aspek behavior, dan aspek emosional. Aspek kognitif yang terdapat dalam angket Student Engagement terdiri atas 9 pertanyaan sehingga rentang skor minimumnya adalah 9 x $1=9$ hingga rentang skor maksimumnya adalah 9 x $5=45$. Luas jarak sebarannya yaitu $45-9=36$. Maka $\sigma=\frac{36}{6}=18$ dan 
$\mu=\frac{45+9}{2}=27$. Berikut ini adalah tabel kategori aspek kognitif mahasiswa berdasarkan perhitungan diatas.

Tabel 4. Tingkatan Kategori Aspek Kognitif Mahasiswa

\begin{tabular}{|c|c|}
\hline & Kategori \\
\hline $\boldsymbol{X}<\mathbf{2 1}$ & Rendah \\
\hline $\mathbf{2 1} \leq \boldsymbol{X}<\mathbf{3 3}$ & Sedang \\
\hline $\mathbf{3 3} \leq \boldsymbol{X}$ & Tinggi \\
\hline
\end{tabular}

Gambaran student engagement pada aspek kognitif berdasarkan hasil angket mahasiswa dengan kategori, tinggi, sedang, dan rendah dapat dilihat pada tabel 5 berikut.

Tabel 5. Gambaran Aspek Kognitif Students’ Engagement

\begin{tabular}{|c|c|c|}
\hline Kategori & Frekuensi & Prosentase \\
\hline Tinggi & 13 & $59 \%$ \\
\hline Sedang & 9 & $41 \%$ \\
\hline Rendah & 0 & $0 \%$ \\
\hline
\end{tabular}

Sedangkan dari segi aspek behaviour, aspek behaviour yang terdapat dalam angket student engagement terdiri atas 13 pernyataan sehingga rentang skor minimumnya adalah 13 x 1=13 hingga rentang skor maksimumnya adalah 13 x $5=65$. Luas jarak sebarannya yaitu $65-13=52$. Maka $\sigma=$ $\frac{52}{6}=8,6$ dan $\mu=\frac{65+13}{2}=39$. Berikut ini adalah tabel kategori aspek behaviour mahasiswa berdasarkan perhitungan diatas.

Tabel 6. Tingkatan Kategori Aspek Behaviour Mahasiswa

\begin{tabular}{|c|c|}
\hline & Kategori \\
\hline $\boldsymbol{X}<\mathbf{3 0 , 4}$ & Rendah \\
\hline $\mathbf{3 0}, \mathbf{4} \leq \boldsymbol{X}<\mathbf{4 7 , 6}$ & Sedang \\
\hline $\mathbf{4 7 , 6} \leq \boldsymbol{X}$ & Tinggi \\
\hline
\end{tabular}

Gambaran student engagement pada aspek behaviour berdasarkan hasil angket mahasiswa dengan kategori, tinggi, sedang, dan rendah dapat dilihat pada tabel 7 berikut.

Tabel 7. Gambaran Aspek Behaviour Engagement Mahasiswa

\begin{tabular}{|l|l|l|}
\hline \multicolumn{1}{|c|}{ Kategori } & \multicolumn{1}{c|}{ Frekuensi } & \multicolumn{1}{c|}{ Prosentase } \\
\hline Tinggi & 10 & $44,5 \%$ \\
\hline Sedang & 12 & $54,5 \%$ \\
\hline Rendah & 0 & $0 \%$ \\
\hline
\end{tabular}

Sedangkan dari segi aspek emosional, aspek emosional yang terdapat dalam angket Student Engagement terdiri atas 5 pernyataan sehingga rentang skor minimumnya adalah $5 \times 1=5$ hingga rentang skor maksimumnya adalah 5 x $5=25$. Luas jarak sebarannya yaitu $25-5=20$. Maka $\sigma=$ $\frac{20}{6}=3,3$ dan $\mu=\frac{25+5}{2}=15$. Berikut ini adalah tabel kategori aspek emosional mahasiswa berdasarkan perhitungan diatas. 
Tabel 8. Tingkatan Kategori Aspek Emosional Mahasiswa

\begin{tabular}{|c|c|}
\hline & Kategori \\
\hline $\boldsymbol{X}<\mathbf{3 0 , 4}$ & Rendah \\
\hline $\mathbf{3 0}, \mathbf{4} \leq \boldsymbol{X}<\mathbf{4 7}, \mathbf{6}$ & Sedang \\
\hline $\mathbf{4 7 , 6} \leq \boldsymbol{X}$ & Tinggi \\
\hline
\end{tabular}

Gambaran student engagement pada aspek emosional berdasarkan hasil angket mahasiswa dengan kategori, tinggi, sedang, dan rendah dapat dilihat pada tabel 9 berikut.

Tabel 9. Gambaran Aspek Emosional Engagement Mahasiswa
\begin{tabular}{|l|l|l|}
\hline Kategori & Frekuensi & Prosentase \\
\hline Tinggi & 10 & $44,5 \%$ \\
\hline Sedang & 12 & $54,5 \%$ \\
\hline Rendah & 0 & $0 \%$ \\
\hline
\end{tabular}

Berdasarkan gambaran aspek dari segi kognitif, behaviour, dan emosional pada tabel 5, 7, dan 9 tersebut, maka dapat dilihat bahwa mahasiswa yang merasa memiliki kategori tinggi lebih banyak pada aspek kognitif, dibandingkan dua aspek lainnya. Selain itu persepsi mahasiswa terkait aspek behavioral dan emosional memiliki jumlah yang seimbang.

\section{Hasil Penelitian berdasarkan Analisis Kualitatif dan Kuantitatif}

Berdasarkan hasil analisis kualitatif dan kuantitatif terdapat perbedaan antara hasil yang diamati oleh observer pada saat pembelajaran dengan hasil angket student engagement yang dijawab oleh mahasiswa. Pada analisis kualitatif menurut pengamatan kelima observer, dari 22 orang mahasiswa hanya 12 orang yang menunjukkan sikap partisipasi yang memperlihatkan student engagement pada saat diskusi kelas dan/atau diskusi kelompok. Sisanya tergolong tidak menunjukkan partisipasi yang terlihat, hanya sebatas terlihat mencatat, menulis, atau menghitung serta raut muka yang menunjukkan mencoba memahami materi yang disampaikan, namun tetap tidak adanya keterlibatan meskipun berada di kelompok yang lebih kecil. Sedangkan hasil analisis kuantitatif terhadap data angket, tidak ada mahasiswa yang merasa student's engagementnya rendah baik dari aspek emosional, kognitif maupun behaviour.

Hal ini menunjukkan bahwa mahasiswa tidak sadar bahwa menunjukkan student engagement yang rendah secara kualitatif. Sehingga dampaknya adalah mereka tidak melakukan introspeksi diri ataupun berusaha untuk lebih baik lagi pada saat pembelajaran di kelas.

Melalui lesson study, guru dapat menelaah mahasiswa yang kurang menunjukkan keterlibatan dalam pembelajaran sehingga dapat diidentifikasi sejak dini langkah apa yang harus dilakukan agar seluruh mahasiswa yang mengikuti proses pembelajaran ikut terlibat di dalamnya.

Pembelajaran yang terencana dan efektif merupakan salah satu tantangan dalam pembelajaran yang dapat difasilitasi dengan mempersiapkan quality lesson plan dan mengatur langkah-langkah pembelajaran yang detail (Sri Gusty, Nurmiati, Muliana et al., 2020). Melalui lesson study, dosen 
dapat mengetahui karakteristik student engagement mahasiswa berdasarkan pengamatan observer. Menurut (Inah, 2015) guru/dosen harus mengetahui karakteristik siswa/mahasiswa untuk menentukan sikap yang berkaitan dengan pembelajaran karena pada dasarnya setiap siswa/mahasiswa memiliki pengalaman dan potensi yang berbeda-beda.

Berdasarkan hasil analisis kualitatif dan kuantitatif melalui proses pembelajaran daring menggunakan lesson study dapat memberikan saran bagi dosen model, bahwa mahasiswa yang kurang menunjukkan keterlibatan pada proses pembelajaran sebaiknya diberikan ruang agar juga dapat berinteraksi pada saat mengikuti pembelajaran dan tidak didominasi oleh mahasiswa yang aktif saja. Selain itu, mahasiswa juga diberikan waktu untuk dapat berpikir dan mencoba sendiri sebelum ditempatkan ke dalam kelompok-kelompok yang lebih kecil. Sehingga nantinya begitu mereka masuk ke kelompok yang lebih kecil, mereka sudah mempunyai pemikiran yang dapat di sampaikan pada diskusi kelompok. Tidak hanya sekedar mengikuti apa yang disampaikan oleh mahasiswa yang lebih aktif. Diharapkan dengan perbaikan-perbaikan tersebut, mahasiswa yang student engagementnya rendah secara kualitatif akan mengikuti hasil angket persepsi mahasiswa terhadap student engagement dirinya.

Students' engagement yang baik dalam pembelajaran daring sangat penting. Students' engagement yang baik berdampak positif terhadap kemampuan self-regulated learning yaitu proses belajar mandiri yang erat kaitannya dengan kepercayaan tentang kemampuan mereka dalam mengerjakan tugas dan bahwa tugas itu menarik dan bernilai untuk dipelajari serta mencapai performa akademik yang maksimal (Lidiawati \& Helsa, 2021). Jika siswa tidak merasa terlibat secara aktif dalam pembelajaran akan berdampak pada minat, motivasi, dan kejenuhan yang merupakan permasalahan utama dalam pembelajaran daring (Sugiharto, 2021).

\section{KESIMPULAN}

Adapun kesimpulan yang diperoleh dari penelitian ini adalah terdapat perbedaan hasil kualitatif dan kuantitatif student engagement pada mahasiswa kalkulus integral. Pada analisis kualitatif, hanya 12 dari 22 orang yang menunjukkan sikap student engagement pada saat diskusi kelas dan/atau diskusi kelompok. Sisanya tergolong tidak menunjukkan partisipasi yang terlihat, hanya sebatas terlihat mencatat, menulis, atau menghitung serta raut muka yang menunjukkan mencoba memahami materi yang disampaikan, namun tetap tidak adanya keterlibatan meskipun berada di kelompok yang lebih kecil. Sedangkan berdasarkan hasil analisis kuantitatif, tidak ada mahasiswa yang merasa student's engagementnya rendah baik dari aspek emosional, kognitif maupun behaviour.

Saran yang dapat diberikan terkait hasil penelitian ini adalah bahwa sebaiknya dosen memberikan mahasiswa ruang bagi mahasiswa yang kurang menunjukkan keterlibatan pada proses pembelajaran agar juga dapat berinteraksi dan tidak didominasi oleh mahasiswa yang aktif saja. Selain itu, mahasiswa juga diberikan waktu untuk dapat berpikir dan mencoba sendiri sebelum 
ditempatkan ke dalam kelompok-kelompok yang lebih kecil. Keterbatasan dalam penelitian ini adalah pembelajaran dilaksanakan secara daring sehingga observer hanya dapat melihat secara terbatas dari ekspresi dan perilaku yang diperlihatkan oleh mahasiswa pada saat pembelajaran melalui layer zoom.

\section{UCAPAN TERIMA KASIH}

Terima kasih kepada Universitas Muhammadiyah Banjarmasin yang telah memberikan dukungan baik moriil dan materiil melalui Lembaga Penelitian dan Pengabdian Masyarakat (LP2M) Universitas Muhammadiyah Banjarmasin. Penelitian ini merupakan Penelitian Hibah bersaing Internal Riset dan Pengabdian Masyarakat Universitas Muhammadiyah Banjarmasin pada Skim Penelitian Unggulan Tahun 2021.

\section{REFERENSI}

Azwar, S. (2015). Penyusunan Skala Psikologi. Pustaka Pelajar.

Belawati, T. (2020). Buku Pembelajaran Online (2nd ed.). Universitas Terbuka Kementerian Pendidikan dan Kebudayaan.

Dewi, T. A. P., \& Sadjiarto, A. (2021). Pelaksanaan Pembelajaran Daring Pada Masa Pandemi Covid19. Jurnal Basicedu, 5(4), 1909-1917. https://doi.org/10.31004/basicedu.v5i4.1094

Dharmayana, I., Masrun, -, Kumara, A., \& Wirawan, Y. (2012). Keterlibatan Siswa (Student Engagement) Sebagai Mediator Kompetensi Emosi Dan Prestasi Akademik. Jurnal Psikologi UGM, 39(1), 76-94.

Fikrie, \& Ariani, L. (2019). Keterlibatan siswa (student engagement ) di sekolah sebagai salah satu upaya peningkaan keberhasilan siswa di sekolah. Seminar Nasional \& Call Paper Psikologi Pendidikan 2019: Menjadi Siswa Yang Efektif Di Era Revolusi Industri 4.0, April 2019, 103110.

Fredricks, J. A., Filsecker, M., \& Lawson, M. A. (2016). Students' engagement, Context, And adjustment: Addressing definitional, Measurement, And methodological issues. Learning and Instruction, 43, 1-4. https://doi.org/10.1016/j.learninstruc.2016.02.002

Inah, ety nur. (2015). Peran Komunikasi Dalam Interaksi Guru Dan Siswa. Al-Ta'dib, 8(2), 150-167.

Lewis, C. (2000). Lesson Study: The Core of Japanese Professional Development" Invited Address to the Special Interest Group on Research in Mathematics Education. Annual Meeting of the American Educational Research Association, 24(28), 46.

Lidiawati, K. R., \& Helsa. (2021). Online learning during covid-19 pandemic : how self-regulated learning strategies impact student engagement? Jurnal Psibemetika, 14(1), 1-10. https://doi.org/10.30813/psibernetika.v14i1.2570

Meyers, S. A. (2008). Using Transformative Pedagogy When Teaching Online. College Teaching, 56(4), 219-224. https://doi.org/10.3200/CTCH.56.4.219-224

Peterson, C. (2006). A Primer in Positive Psychology. Oxford University Press. 
Siahaan, M. (2020). Dampak Pandemi Covid-19 Terhadap Dunia Pendidikan. Jurnal Kajian Ilmiah, 1(1), 73-80. https://doi.org/10.31599/jki.v1i1.265

Sri Gusty, Nurmiati, Muliana, O. K. S., Ni Luh Wiwik Sri Rahayu Ginantra, M. A. M., Andriasan Sudarso, Natasya Virginia Leuwol, A., Andi Arfan Sahabuddin, Puji Hastuti, A. Y. S., Tia Metanfanuan, Lulu Jola Uktolseja, Jamaludin, S. G., \& Karwanto, Erni Rante Bungin, Jamaludin, S. Y. W. (2020). Belajar Mandiri: Pembelajaran Daring di Tengah Pandemi Covid19. Yayasan Kita Menulis.

Sugiharto, F. (2021). Gambaran Student Engagement pada Pembelajaran Daring Selama Pandemi Covid-19 di Fakultas Keperawatan Universitas Padjajaran (Doctoral Dissertation).

Syah, M. (2009). Psikologi Pendidikan Suatu Pendekatan Baru. Remaja Rosdakarya.

Takahashi, A., \& Yoshida, M. (2004). Ideas for establishing communities Lesson-Study Communities. Teaching Children Mathematics, May, 436-443.

Wang, M. Te, \& Holcombe, R. (2010). Adolescents' perceptions of school environment, engagement, and academic achievement in middle school. American Educational Research Journal, 47(3), 633-662. https://doi.org/10.3102/0002831209361209

Widiyono, A. (2020). Efektifitas Perkuliahan Daring (Online) pada Mahasiswa PGSD di Saat Pandemi Covid 19. Jurnal Pendidikan, 8(2), 169-177. https://doi.org/10.36232/pendidikan.v8i2.458 